\title{
Qualitative analysis of Orzooiyeh plain groundwater resources using GIS techniques
}

\author{
Mohsen Pourkhosravani* \\ Assistant Professor, Department of Geography Shahid Bahonar University of Kerman, Kerman, Iran
}

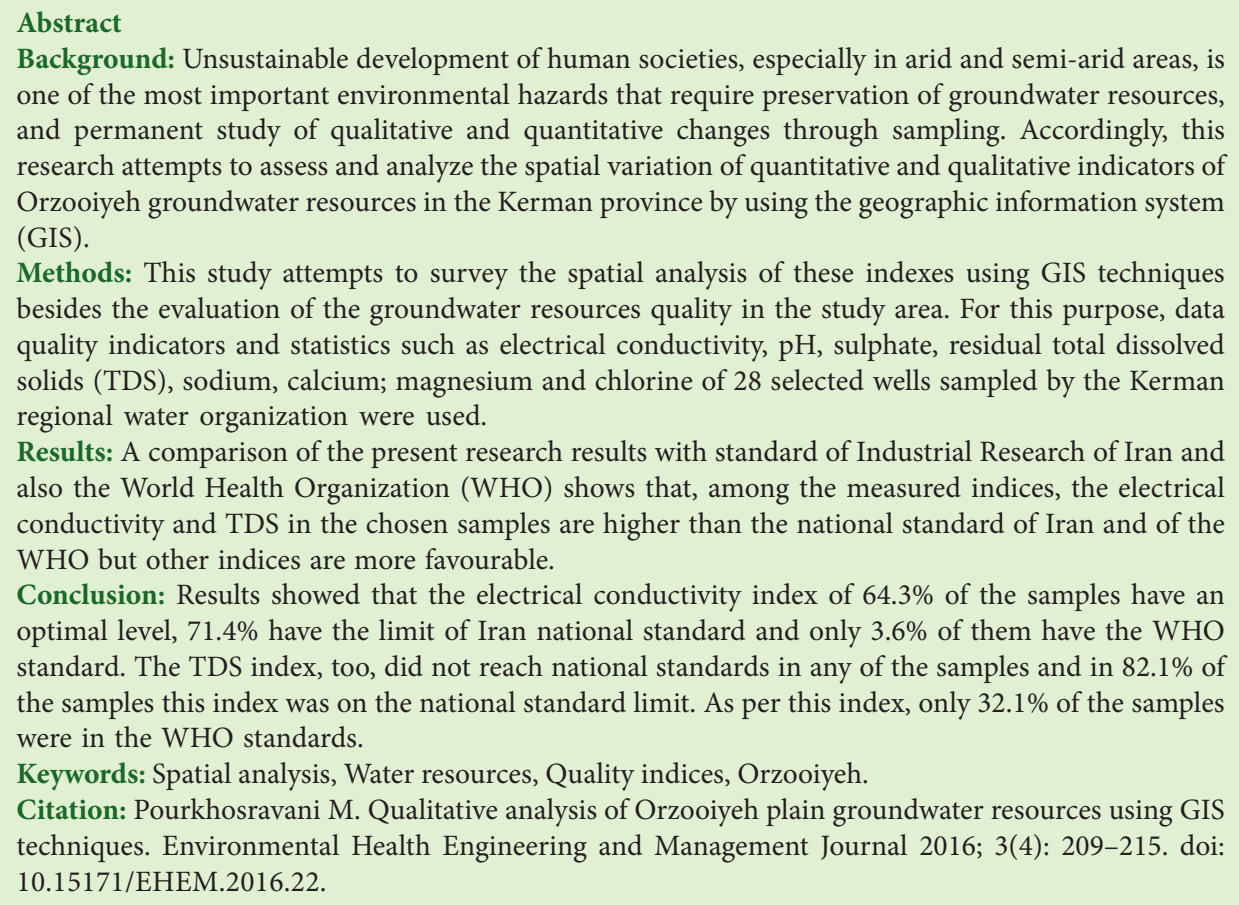

\section{Introduction}

According to environmental conditions in arid and semiarid areas, groundwater is among the most important sources of drinking water and agriculture in these areas. Groundwater is an important part of the ecosystem renewable water resources that has suffered qualitative and quantitative changes because of improper management of extraction that has directly or indirectly caused the destruction of other resources. Increase population and the overdraw of groundwater in recent years pose a serious risk to the quantity and quality of limited water resources. This has made planning to protect water resources so much more important. The main purpose of qualitative surveys is the preservation of public and consumer health. For this, making adequate water available, and adapting it to the physical, chemical, biological and radiological codification standards are necessary (1). It should be noted that changes in groundwater quality is a function of the physical and chemical indicators that are also strongly influenced by the geological structure of the area and human activities (2). In general, today, the unstable development of human societies is one of the most important environmental hazards that make imperative the preservation of groundwater resources and a permanent study of its qualitative and quantitative changes through sampling (3). Because groundwater's quality has been measured in a scale of time and space, and its properties cannot be assumed in fixed time and space, the preparation salinity and mineral maps can be an important step towards the proper utilization of the water resource (4). Various researchers have done extensive investigations in relation to the quantity and quality of groundwater in different regions according to the importance of groundwater resources and sustainable development of arid and semi-arid areas. A study of temporal and spatial changes in the Mehriz Baharan plain shows that the groundwater in $48 \%$ of the study area has a strict level and in 52\% have moderate to low levels (5). 
Moreover, assessment and mapping of the qualitative and quantitative destruction of ground water resources in the Firuzabad plain show that $93 \%$ of the study area faces the extreme danger of the destruction of groundwater resources (6). Too assessment of groundwater quality and its suitability for drinking and agricultural uses in the Oshnavieh area, showed fluoride and nitrate are within the permissible limits for human consumption and crops as per the international standards (7). Another study evaluated the qualitative and quantitative changes of groundwater resources in the Amol and Babol plains, showing a slight decrease in the groundwater level and an improvement in the water quality (8). Analytical methods of assessing underground water quality are mainly based on classical statistics and graphical methods involving a limited number of samples and lack of spatial correlation of samples with qualitative parameters. A change from classical to systematic attitudes nowadays has led to a growing interest in the use of geostatistical methods when doing spatial analysis of quantity and quality in groundwater resources. Geostatistics is a calculation process in which the value of a quantity at a given point is based on the weight assigned to clear information about adjacent parts. Since the quantity and quality of groundwater has temporal and spatial variations, the geostatistical techniques are important for taking into account the spatial correlation of data and expressing them in the form mathematical models (9). Generally, among geostatistical methods, the kriging method using the lowvariance coefficient is more important in the evaluation of qualitative and quantitative changes of groundwater resources (10). Accordingly, this research attempts to assess and analyze the spatial variation of quantitative and qualitative indicators of Orzooiyeh groundwater resources in the Kerman province by using the geographic information system (GIS).

\section{Methods}

Orzooiyeh is a tectonic plain situated to the south-west of Kerman between $21^{\prime} 56^{\circ}$ to $35^{\prime} 56^{\circ}$ eastern longitude and between $27^{\prime} 28^{\circ}$ to $45^{\prime} 28^{\circ}$ northern latitude (Figure $1)$. This plain probably emerged in the late Pliocene and early Pleistocene and due to compression phases. The value of the longitudinal axis has a north-west to south- east trend and is structurally in Sanandaj-Sirjan zone and Zagros. Hydrologically, the Orzooiyeh plain is the part of the entire basin that flows into the Persian Gulf and the average height of the basin's mountainous part is $1770 \mathrm{~m}$, and $1100 \mathrm{~m}$ is the average height of the sliding Dolatabad. This study is based on descriptive and analytical methods and field study. In order to spatially analyse quality of the Orzooiyeh plane groundwater resources, annual indices of qualitative data of electrical conductivity, $\mathrm{pH}, \mathrm{SO}_{4}$, residual total dissolved solids (TDS), sodium, calcium, magnesium, and chlorine related to 28 selected wells were gathered from the Kerman regional water organization samples in 2011 by doing a complete chemical analysis. Results of this study were achieved by a comparison of the standards of the World Health Organization (WHO) (11) and the Institute of Standards and Industrial Research of Iran (ISIRI) (12). In the next step, the zoning of groundwater quality was conducted by the kriging method on the basis of various indicators and using Arc GIS software. In geostatistics we can estimate the quantity value in another point with known coordinates by having the quantity value in known coordinate. This is possible provided the coordinate of an unknown value placed in the domain that has a spatial structure (13). Estimation of variable with distribution and spatial structure and evaluation of error with this estimation is called kriging (14). This estimator has the following characteristics: 1. The estimated values for the unknown points are the linear combination of adjacent samples. So:

$$
\mu K=\sum_{i=1}^{n} \lambda_{i} X_{i}
$$

Where $\mu$ к is the kriging estimation and $\lambda_{\mathrm{i}}$ is the allocated weights vector to samples. In other words, an estimated value is had by assigning weights $\lambda_{\mathrm{i}}$ to known amounts measured in adjacent points $\left(\mathrm{x}_{\mathrm{i}}\right)$.

2. It is unbiased, meaning, its mathematical expectation is equal to the actual average $(w \mu)$ samples.

$E=(\mu \kappa-\mu w)=0$

3. The mean square error has the least possible value. That means:

$E\left[(\mu \kappa-\mu w)^{2}\right]=\operatorname{amin}$

In this method, after measuring the amount of variable for several samples with regard to their situation, the amount

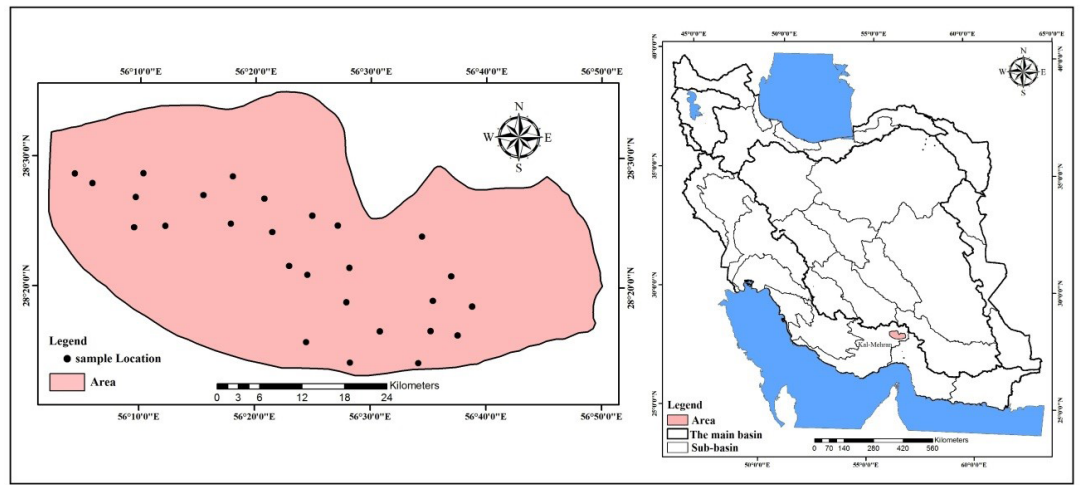

Figure 1. Location of the study area and sampling wells. 
of variable of non-sampling points is also estimated by considering their position and the distance from common points (15). One of the most important characteristics of the kriging method is that, for each estimate, the relative error can be calculated and the number of points in the adjacent is usually about 10 points. So we can estimate and calculate the confidence interval for each estimated amount. Since in classical methods these operations are ineffective, the zoning maps of each indicator were prepared with the help of Arc GIS software.

\section{Results}

Table 1 shows the descriptive statistical characteristics of quality indicators measured from the study area of underground sources indicators by comparing these indices using standard WHO standards and Industrial Research Organization of Iran.

The results show the maximum amount of electrical conductivity near the centre of the area relates to well No. $8 \mathrm{a}$ and the lowest is for well No. 28. The amount of dissolved solids in the sample wells is also similar to electrical conductivity, with a maximum of $3991 \mathrm{mg} / \mathrm{L}$ in well No. 26, and a minimum of $320 \mathrm{mg} / \mathrm{L}$ in well No. 28 . According to the table results, the highest level of ${ }_{2} \mathrm{H}$ in water resources studied is related to wells No. 20, 22 and 25 at the rate of 7.8 and the lowest is for wells No. 9 and 28 with ${ }_{2} \mathrm{H} 7$. On the other hand, the highest amount of sulphate is in Well No. $8(20.2 \mathrm{mg} / \mathrm{L})$ and the lowest rate is for well number $28(0.8 \mathrm{mg} / \mathrm{L})$. The maximum amount of chlorine relates to well No. $8(17.8 \mathrm{mg} / \mathrm{L})$ and the lowest for well number $28(0.5 \mathrm{mg} / \mathrm{L})$. The results show, the maximum amount of sodium relates to Well No. 1 with $67.2 \mathrm{mg} / \mathrm{L}$ and the lowest amount to well No. 28 with 15.1 $\mathrm{mg} / \mathrm{L}$. The highest amount of magnesium is for well No. 8 with the amount of $11.6 \mathrm{mg} / \mathrm{L}$ and the least is for well No. 1 with a rate of $0.7 \mathrm{mg} / \mathrm{L}$. On the other hand, the highest amount of calcium is for well No. 8 with the amount of $14.4 \mathrm{mg} / \mathrm{L}$ and the least is for well No. 1 and 2 with a rate of $1.5 \mathrm{mg} / \mathrm{L}$.

Generally, the table indicates that the values of indicators $\mathrm{pH}$, magnesium, calcium, sulphate, chloride and sodium in groundwater resources in the study area were lower than

Table 1. Statistical data of groundwater quality indicators and compared to the standard values

\begin{tabular}{|c|c|c|c|c|c|c|c|c|c|c|}
\hline \multirow{2}{*}{ No. } & \multirow{2}{*}{ Sample well } & \multirow{2}{*}{ Depth (m) } & \multirow{2}{*}{ ph } & \multirow{2}{*}{$\begin{array}{c}\text { mic-mho } \\
\text { Ec }\end{array}$} & \multicolumn{5}{|c|}{$\mathrm{mEq} / \mathrm{L}$} & \multirow{2}{*}{$\mathrm{Na} \%$} \\
\hline & & & & & $\mathrm{Mg}$ & $\mathrm{Ca}$ & TDS & SO4 & $\mathrm{Cl}$ & \\
\hline 1 & Sarghaz Dolatabad & 120.0 & 7.3 & 656 & 0.7 & 1.5 & 426 & 1.1 & 1.8 & 67.2 \\
\hline 2 & Dolatabad Esa Safi nataj & 110.0 & 7.3 & 818 & 2.5 & 1.5 & 532 & 2.2 & 2.8 & 50 \\
\hline 3 & Dolatabad Mahmod dolati & 120.0 & 7.4 & 660 & 1.4 & 1.6 & 429 & 1.9 & 1.8 & 53.8 \\
\hline 4 & Ghaderabad Abdollah Shafiei & 110.0 & 7.5 & 850 & 2.2 & 3.6 & 533 & 3.3 & 2.4 & 34.8 \\
\hline 5 & Aliabad Shamshirbar & 130.0 & 7.3 & 1088 & 3.3 & 3.1 & 707 & 3.6 & 4.2 & 42.9 \\
\hline 6 & Rahmatabad & 120.0 & 7.3 & 2250 & 8.2 & 4.8 & 1463 & 13.8 & 7 & 48 \\
\hline 7 & Vakilabad Honarestan & 120.0 & 7.3 & 1295 & 4.5 & 2.5 & 842 & 3.9 & 5.5 & 45.7 \\
\hline 8 & Kachalabd Keshavarzan & 130.0 & 7.4 & 4160 & 11.6 & 14.4 & 2704 & 20.2 & 17.8 & 38.1 \\
\hline 9 & Damaneh Tiraft & 120.0 & 7 & 2870 & 8.2 & 8.8 & 1866 & 14.4 & 14 & 45.9 \\
\hline 10 & Nosratabd & 110.0 & 7.2 & 1100 & 5.4 & 2.1 & 715 & 4.8 & 3.5 & 36.4 \\
\hline 11 & Vakilabad Mostazafan & 100.0 & 7.5 & 1399 & 4.6 & 3.4 & 909 & 4.3 & 6.8 & 44.1 \\
\hline 12 & Aliabd Sepahani & 120.0 & 7.5 & 2160 & 7.9 & 3.1 & 1404 & 12.1 & 7.2 & 52.2 \\
\hline 13 & Soltanabd masoudi & 100.0 & 7.4 & 1495 & 4.6 & 3.8 & 972 & 4.3 & 7.9 & 44.7 \\
\hline 14 & Allahabad & 120.0 & 7.4 & 1728 & 5.7 & 3.9 & 1123 & 4.9 & 9.3 & 46.4 \\
\hline 15 & Takhte khaje & 120.0 & 7.3 & 1928 & 8 & 6 & 1253 & 9.3 & 8.4 & 32.4 \\
\hline 16 & Aliabad Shamshirbar & 110.0 & 7.5 & 1023 & 2.9 & 1.9 & 665 & 4.4 & 2.5 & 56.8 \\
\hline 17 & Chilabad & 130.0 & 7.5 & 2520 & 9.8 & 3.2 & 1638 & 14.4 & 9 & 52.6 \\
\hline 18 & Dolatabad Didar bahrami & 100.0 & 7.1 & 935 & 2 & 2.4 & 608 & 3.9 & 3 & 53.2 \\
\hline 19 & Hoseinabad Zabihollahe Bahari & 100.0 & 7.7 & 995 & 3.5 & 2 & 647 & 4 & 2.5 & 45 \\
\hline 20 & Ghadeabad Mansouri & 110.0 & 7.8 & 910 & 2.3 & 1.9 & 592 & 3.7 & 2.4 & 56.3 \\
\hline 21 & Allahabad Dasht berm & 110.0 & 7.7 & 1385 & 7 & 2 & 900 & 8.5 & 3.2 & 41.2 \\
\hline 22 & Dolatabd Ahmad Ghanji & 100.0 & 7.8 & 677 & 1.7 & 1.7 & 440 & 2.2 & 1.8 & 48.5 \\
\hline 23 & Ghaleno Alireza Saberi & 120.0 & 7.5 & 2160 & 5.8 & 5.8 & 1404 & 4.2 & 15 & 47.3 \\
\hline 24 & Vakilabad Ghasem Maket & 120.0 & 7.4 & 2770 & 7.8 & 8.6 & 1801 & 10.3 & 14 & 39.9 \\
\hline 25 & Gholnaabad Keramat Almasi & 110.0 & 7.8 & 836 & 2.9 & 1.6 & 543 & 3.8 & 2.1 & 47.1 \\
\hline 26 & Ghaemabad Manochehr Tavakoli & 130.0 & 7.7 & 614 & 3 & 2.4 & 3991 & 3.9 & 2 & 44.3 \\
\hline 27 & Tale Yatim Vakilabad & 120.0 & 7.7 & 751 & 1.6 & 3.4 & 488 & 2.5 & 1.5 & 33.3 \\
\hline 28 & Hosienabad Kalian & 120.0 & 7 & 492 & 1.5 & 3 & 320 & 0.8 & 0.5 & 15.1 \\
\hline \multicolumn{2}{|c|}{ Average } & 115.4 & 7 & 1447 & 4.4 & 3.7 & 1022 & 5.8 & 5.4 & 44.4 \\
\hline \multicolumn{2}{|c|}{ Minimom } & 100 & 7 & 492 & 0.7 & 1.5 & 320 & 0.8 & 0.5 & 15.1 \\
\hline \multicolumn{2}{|c|}{ Maximum } & 130 & 7.8 & 4160 & 11.6 & 14.4 & 3991 & 20.2 & 17.8 & 67.2 \\
\hline \multicolumn{2}{|c|}{ Iran national } & vel & $6.5-8.5$ & 1500 & 30 & 75 & 100 & 250 & 250 & 200 \\
\hline \multicolumn{2}{|c|}{ standard } & mit & $6.5-9$ & 2000 & 150 & 250 & 1500 & 400 & 400 & 200 \\
\hline \multicolumn{3}{|c|}{ World Health Organization } & $6.5-8.5$ & 600 & 50 & 75 & 600 & 200 & 200 & 200 \\
\hline
\end{tabular}


those set by the WHO and the Iran Industrial Research Organization standards, and groundwater resources have a very good grade for these indices. However, according to the results in this table, the electrical conductivity in $64.3 \%$ of samples has an optimal level, and $71.4 \%$ has the Iran national standard, and only $3.6 \%$ of these resources of electrical conductivity have the WHO standard. TDS have not been optimal in the light of national standards in any of the samples, and $82.1 \%$ of these samples have standard limit. The value of this index in $32.1 \%$ of samples is of standard value. In general, according to the results shown in the table, average indices of electrical conductivity and TDS in the groundwater resources of the study area conform to the national standard of Iran, and average value of these indices is higher than the optimal level of the national standard and also of the WHO.

\section{Discussion}

As mentioned, the zoning of the qualitative indices of groundwater resources in the study area was done using the kriging method by the Arc GIS software. Figure 2 shows the zoning of study area based on electrical conductivity. According to this figure, the amount of electrical conductivity of the area bordering the centre has increased.

Table 2 also shows classes and degrees of risk in electrical conductivity.

It is obvious from a comparing of the mean of electrical

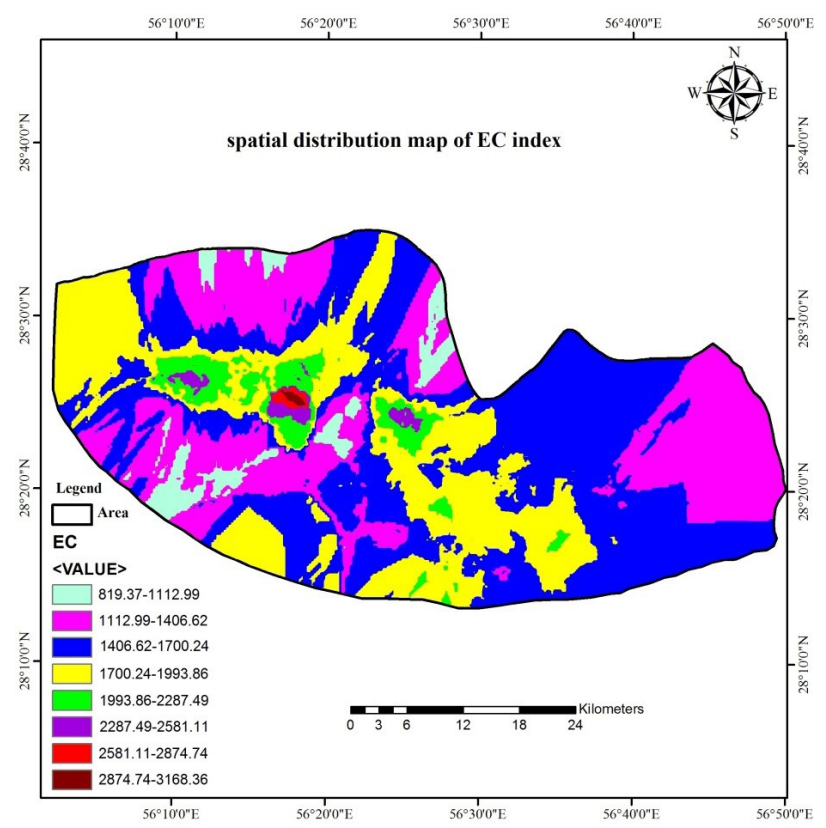

Figure 2. Zoning of electrical conductivity.

Table 2. Classes and degrees of risk in electrical conductivity

\begin{tabular}{lll}
\hline Degree of risk & Class of risk & Domain $(\boldsymbol{\mu}$ Siemens $/ \mathrm{cm})$ \\
\hline 1 & No risk & $0-250$ \\
2 & Low risk & $250-750$ \\
3 & Mean & $750-2250$ \\
4 & Severe risk & $2250-5000$ \\
5 & Severe hazard risk & $\geq 5000$ \\
\hline
\end{tabular}

conductivity with class and degree of the risk shown in this table that groundwater resources in the study area have a middle class, based on these indicators. But according to the zoning plan, this water resources index is of the central part of the region that is in the severe-hazard class.

In American salinity laboratory, water with electrical conductivity less than $953 \mu \mathrm{Siemens} / \mathrm{cm}$ is appropriate and can be used to irrigate salt-sensitive plants. Water with 753 to $953 \mu$ Siemens/cm salinity requires proper drainage management. Water with 753 to $9953 \mu$ Siemens/ $\mathrm{cm}$ salinity and water with electrical conductivity of more than $9.953 \mu$ Siemens/cm is not suitable for irrigation unless tolerant plants are planted and leaching is made possible with proper drainage (16).

Figure 3 shows zoning of TDS in the study area. The TDS in the water except suspended sediments, colloidal and dissolved gases include mineral salts with a lesser concentration of organic substances such as carbonate, bicarbonate, chloride, sulphate, nitrate, sodium, potassium, calcium and magnesium (17). The higher the amounts of these substances in water, the greater will be the water's electrical conductivity and salinity. Moreover, according to the zoning map of dissolved solids in the groundwater resource of the area, the more we move from the border area towards the centre, the amounts of soluble substances increases.

In general, electrical conductivity represents the cationic and anionic salts dissolved in water, which can accelerate electricity flow in water. The more the electrical conductivity of water sample, the greater is the amount of salts to be is found in it, and can be an indication of poor quality. The electrical conductivity of water depends on soluble salts. Hence, high electrical conductivity of water indicates high levels of soluble salts and ions in it.

Figure 4 shows that the amount of $\mathrm{pH}$ increases from the border to the centre and somewhat to the east. As can be

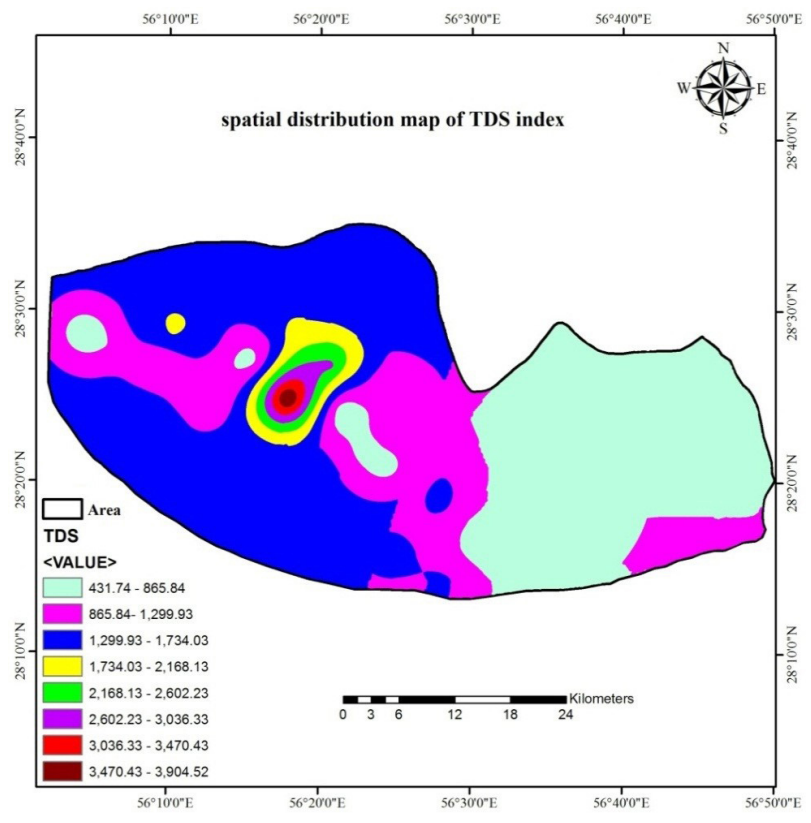

Figure 3. Zoning of dissolved solids. 
seen, the water resource of the area in general deals with good ph. It should be noted that, although $\mathrm{pH}$ does not directly affect consumer heath, it is one of the factors affecting water quality and the guideline value is not based on health effects (18).

According to the sulphate zoning plan in the study area (Figure 5) the maximum amount of sulphate in the groundwater resources is found at the centre of the region. Probably the amount of sulphate concentration has increased between layers of calcareous rocks of gypsum compounds and sulphated compounds with the interaction of these rocks with groundwater and their dissolution in water.

Usually, a large amount of clay and gypsum increases

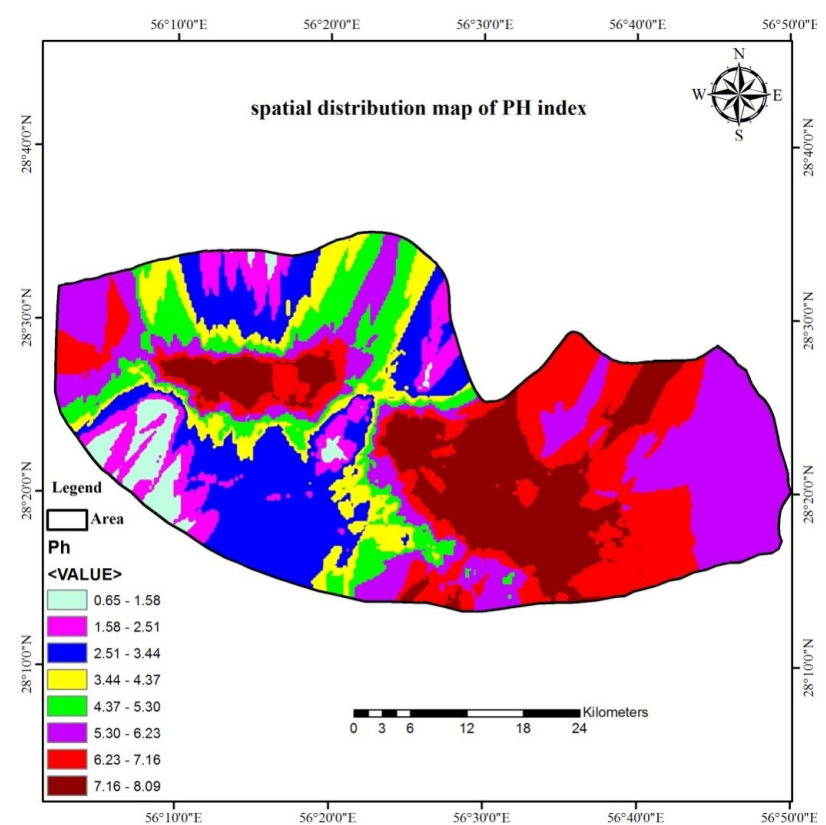

Figure 4. Zoning of $\mathrm{pH}$.

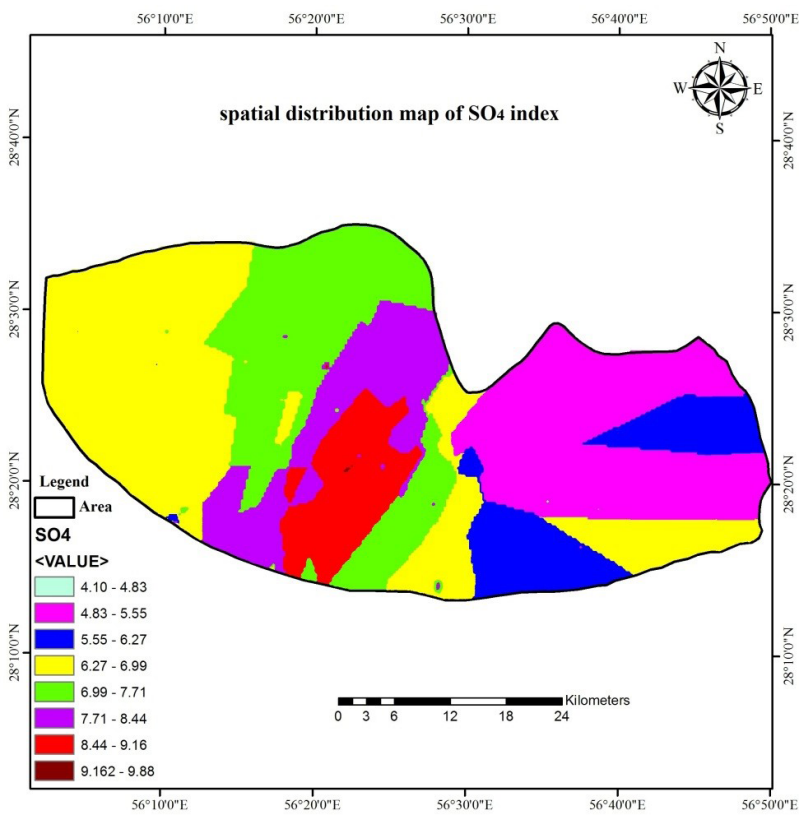

Figure 5. Zoning of sulphate. sulphate concentration (19). However, the results show the level of sulphate in the groundwater under study is much lower than the WHO standards and the limit set by the ISIRI.

According to the zoning map of chlorine in the study area (Figure 6), a higher indication of chlorine is seen in the northern and central regions and a decline in its presence in groundwater towards the east. The results show the presence of fine-grained sediments in this part of the region, which are among factors increasing the presence of chloride in water resources.

According to Figure 7, a higher sodium index pertains to the southern and south-eastern parts of the study area, with its concentration decreasing as we move to the north-

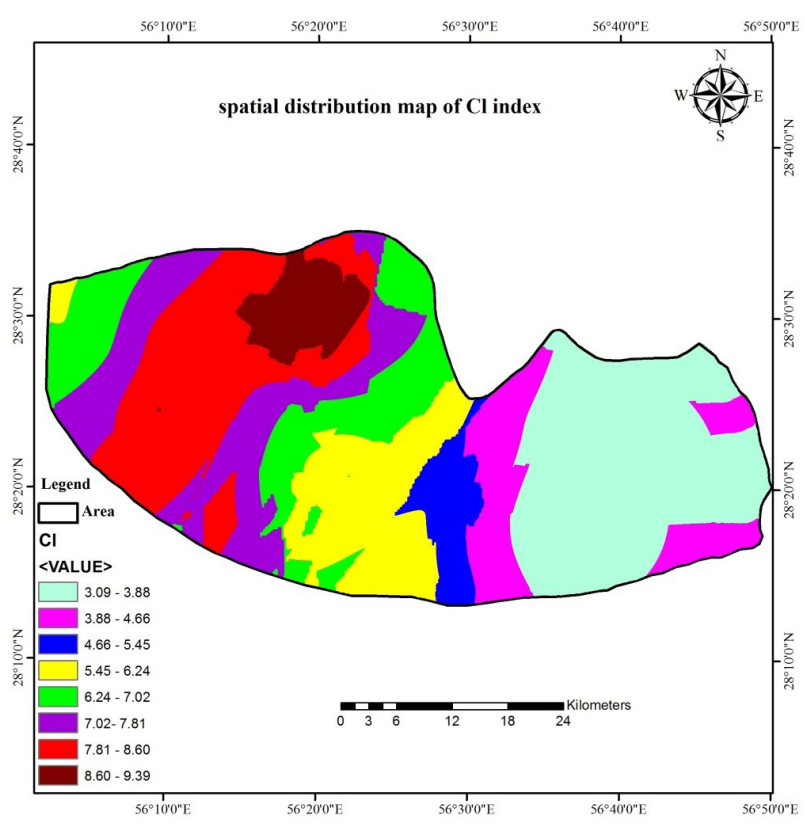

Figure 6. Zoning of chlorine.

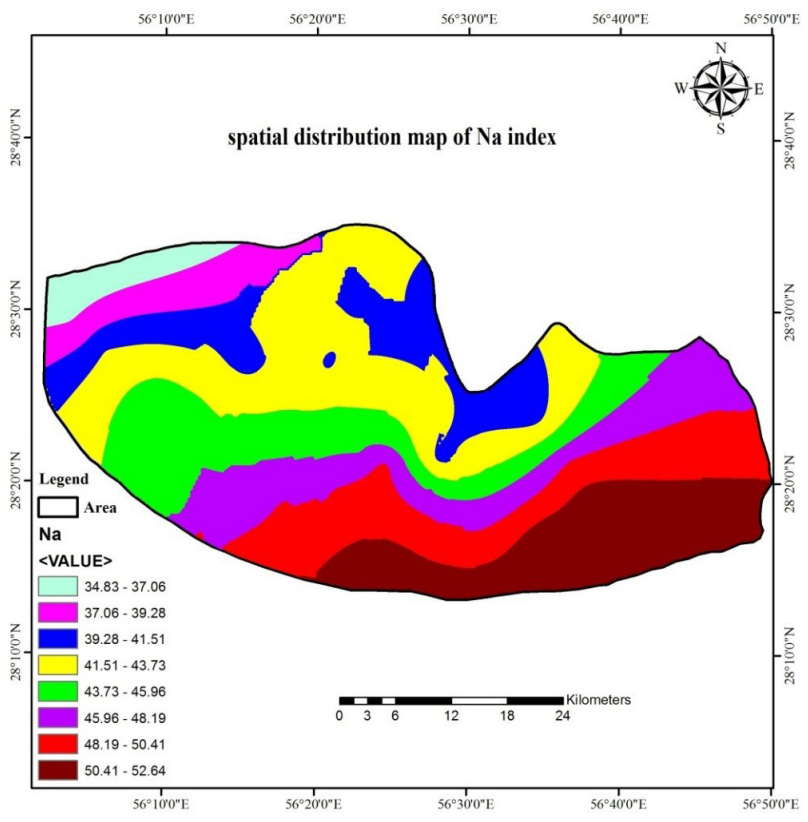

Figure 7. Zoning of sodium. 
west region.

Generally, uncontrolled exploitation of groundwater resources is increasing the amount of magnesium. With a fall in groundwater levels, waters with salinity turn bitter, a taste contributed by the magnesium factor.

Moreover, as shown in Figure 8, there is a higher concentration of magnesium in the vicinity of the centre and north of it, with presence declining from this part to the border region, and especially in the eastern area. According to the spatial distribution of calcium (Figure 9), the maximum amount of calcium is found in the western part of the study area, while its concentration keeps diminishing as we move towards the east. Chile and limestone formations in the western part amount increases

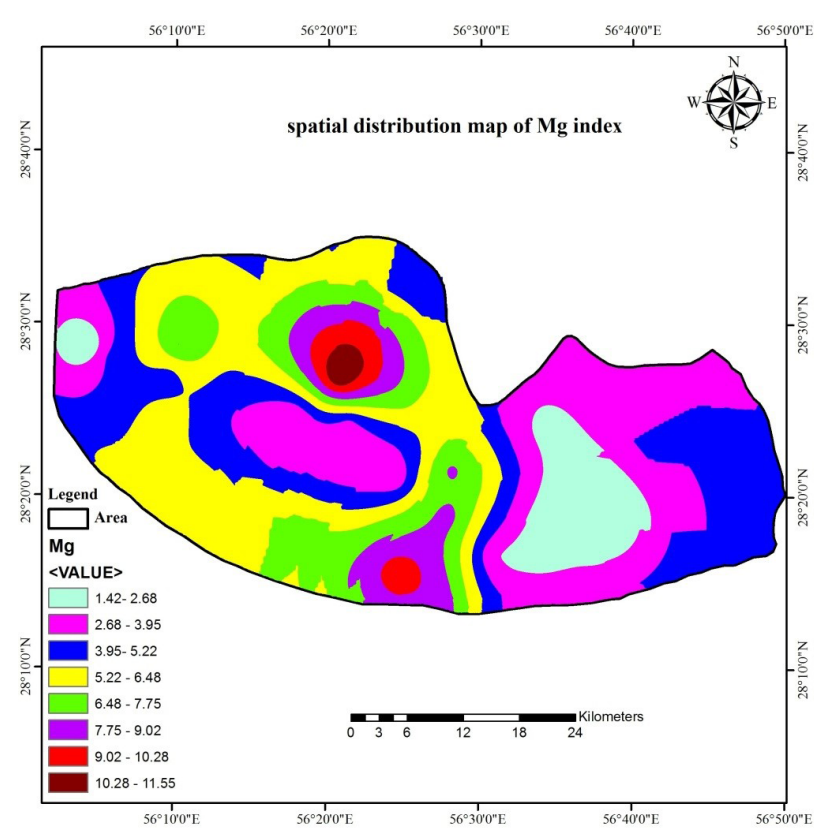

Figure 8. Zoning of magnesium.

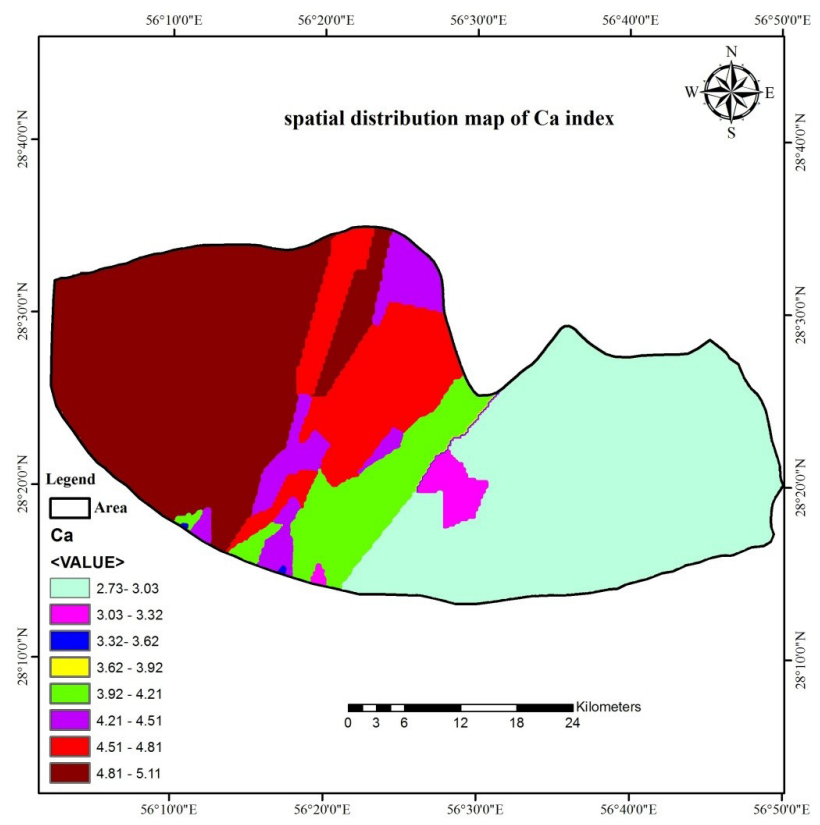

Figure 9. Zoning of calcium.
Table 3. As standard elements in groundwater resources

\begin{tabular}{lccccc}
\hline Scale & SO4 & Ca & TDS & mg & Cl \\
\hline Good & $<3.02$ & $<5$ & $<500$ & $<3$ & $<4.92$ \\
Appropriate & $3.02-5.83$ & $5-10$ & $500-1000$ & $3-5$ & $4.92-9.85$ \\
Inappropriate & $5.83-12.08$ & $10-20$ & $1000-2000$ & $5-10$ & $9.85-19.71$ \\
Bad & $12.08-23.95$ & $20-40$ & $2000-4000$ & $10-20$ & $19.71-39.43$ \\
\hline
\end{tabular}

the presence of this element in the underground water resources. However, value of this element in the region's water resources is reduced with the expansion of alluvial formations towards the centre and the eastern region.

Table 3 shows the standard elements in groundwater resources.

A comparison of the results of this table and the results of this study shows that the average amount of these elements in groundwater resources in the study area is within acceptable limits. Only the average amount of TDS is inadequate.

\section{Conclusion}

Quantification of water quality is an integral part of scientifically based water resources management (20). Because water quality monitoring not only improves water quality but also involves economic value in the process of producing clean water and is an important factor in reducing production and water treatment costs. Some of these salts in water are essential for human health, while amounts higher than the standard limit pose a health hazard. Hence, clean water guarantees public health, and the first step in understanding water is a survey of water quality parameters (21). Accordingly, this research evaluated the qualitative indices and zoning of these indices in the study area of groundwater resources. It should be noted that the concentration of ions in groundwater is usually dependent on the spatial position of each point and the geographical coordinates of such points. In the study area, the flow of groundwater is from the north and east to the south and west of the plains. Hence, the more it moves from the north and the north-west to the south and south-east and especially the basin centre, composed of fine-grained, the quality of underground water keeps deteriorating. In general, the existence of two salt domes such as the Zagros Thrust and spring spas in the basin, containing sulphur compounds, and, in addition, the nature of the plains inside the basin serving as evaporation plain with saline soil and high salt causes the water quality to improve with basic flow. These factors have led electrical conductivity of groundwater resources to increase from $69 \mu$ Siemens at the basin entrance to $2000 \mu$ Siemens in the centre. According to what was said above, results show that between measured indices the two indices of electrical conductivity and total dissolved salts increase from the standards of Iran national standard organizations and the WHO. Also the $\mathrm{pH}$ of water resources increase and quality resources find neutral and slightly alkaline desire from the centre of the area toward East. Thus the water resources quality in the 
study area drops from the north and north-west as one moves towards the centre, south and south-east basin due to topographic and geological characteristics of the area.

\section{Acknowledgments}

Special thanks to Kerman regional water organization that offered the qualitative data for the accomplishment of this research.

\section{Ethical issues}

There were no ethical issues involved preparing this article.

\section{Competing interests}

None to be declared.

\section{Author' contribution}

MP is the single author of the paper.

\section{References}

1. Rahmani Z, Gholami M, Khoshnevis Zadeh A, Rezayee Kalantari R. Investigation of Buin Zahra drinking water resources quality by using of GWQI. J Alborz Univ Med 2013; 3(2): 147-55. [In Persian].

2. Pourakbar M, Mosaferi M, Shaker Khatibi M, Moradi A. Groundwater quality assessment from a hydrogeochemical viewpoint a case study of Sarab county. J Water Wastewater 2015; 26(3): 116-26. [In Persian].

3. Zreabyaneh H. Spatial analysis of groundwater resources quality parameters of Hamadan-Bahar plain. Geography and Environmental Hazards 2014; 2(8): 65-86. [In Persian].

4. Heydari E, Ekrami M, Nasabpour S. Study temporal and spatial groundwater quality using geostatistical (case study: Yazd-Ardakan plain). Desert Ecosystems Engineering Journal 2015; 4(6): 63-70. [In Persian].

5. Sahebjalal E, Dehghani F, Tabatabaizadeh M. Investigating spatio-temporal variations of groundwater quality using Kriging method. Journal of Science and Technology of Agriculture and Natural Resources 2013; 17(65): 51-61. [In Persian].

6. Masoudi M, Barzegar S. Assessment and mapping of qualitatative and quantitative severity degradation of groundwater resourses using the modified IMDPA desertification model and GIS. A Case Study: Firuz-abad plain of Fars province. Journal of Irrigation \& Water Engineering 2015; 5(20): 86-95. [In Persian].

7. Aghazadeh N, Asghari Mogaddam A. Assessment of groundwater quality and its suitability for drinking and agricultural uses in the Oshnavieh area, Northwest of Iran. Journal of Environmental Protection 2010; 1(1): 30-40. doi: 10.4236/jep.2010.11005

8. Afzali A, Shahedi K. Investigation on Trend of Groundwater
Quantity-Quality Variation in Amol-Babol Plain. Journal of Watershed Management Research 2014; 5(10): 144-56. [In Persian].

9. Sun Y, Kang S, Li F, Zhang L. Comparison of interpolation methods for depth to groundwater and its temporal and spatial variations in the Minqin oasis of northwest China. Environ Model Softw 2009; 24(10): 1163-70. doi: 10.1016/j. envsoft.2009.03.009.

10. Theodossiou N, Latinopoulos P. Evaluation and optimization of groundwater observation networks using the kriging methodology. Environ Model Softw 2006; 22(7): 991-1000. doi: 10.1016/j.envsoft.2005.05.001.

11. World Health Organization (WHO). Guidelines for Drinking-Water Quality. 3rd ed. Geneva: WHO; 2008.

12. Institute of Standard and Industrial Research of Iran. Drinking Water: Physical and Chemical Characteristics. 5th ed. Iran: Institute of Standard and Industrial Research of Iran; 2009. [In Persian].

13. Asakereh H. Kriging Application in Climatic Element Interpolation A Case Study: Iran Precipitation in 1996. Journal of Geography and Development 2008; 6(12): 25-42. [In Persian].

14. Davis JC. Statistics and Data Analysis in Geology. New York: John Wiley \& Sons; 1973. p. 550.

15. Salehi $\mathrm{H}$, Zaynivand $\mathrm{H}$. Survey of the quality of underground water for drinking and agriculture, and select the most appropriate spatial interpolation method for special interpolation (Case study: West of the city of Marivan). Ecohydrology Magazine 2014; 3: 153-66. [In Persian].

16. Moqimi H, Zare Eghbalabadi M. Qualitative zoning of heart aquifer (Yazd province) for agricultural purposes using GIS. The First National Conference on the Use of Advanced Spatial Analysis Models (remote sensing and GIS) in Spatial Planning; 2014 March 5-6; Islamic Azad University of Yazd. [In Persian].

17. Sedaghat M. Land and Water Resources (Groundwater). Tehran: Payam Noor University Press; 2008. p. 110-121. [In Persian].

18. WHO. The guidelines: a framework for safe drinking-water. In: WHO, ed. Guidelines for Drinking Water Quality. 3rd ed. Geneva: WHO; 2006. p. 6-8.

19. Hudak PF, Sanmanee S. Spatial patterns of nitrate, chloride, sulfate, and fluoride concentrations in the Woodbine Aquifer of north-central Texas. Environ Monit Assess 2003; 82(3): 311-20. doi: 10.1023/A:1021946402095.

20. Parparov A, Gal G, Hamilton D, Kasprzak P, Ostapenia A. Water quality assessment, trophic classification and water resources management.Journal of Water Resource and Protection 2010; 2(10): 907-15. doi: 10.4236/jwarp. 2010.210108

21. Shariat Panahi M. Principle of quality and treatment of water and wastewater. 5th ed. Tehran: Tehran University Press; 1998. p. 114-29. [In Persian]. 